Journal of Accident and Emergency Medicine 1995

12, 259-261

\title{
General anaesthesia in accident and emergency departments
}

\author{
K.F.H. TEALE, ${ }^{1}$ I.R. SELBY ${ }^{1} \&$ M.R. JAMES 2 \\ ${ }^{1}$ Departments of Anaesthesia and ${ }^{2}$ Accident and Emergency Medicine, Royal Preston Hospital, \\ Fulwood, Preston PR2 4HT, UK
}

\section{SUMMARY}

Potential problems with the provision of general anaesthesia in accident and emergency (A\&E) departments were investigated by sending consultants in A\&E a postal questionnaire asking for their views on the quality of the anaesthetic service available to their department. Of the 129 consultants replying, $31 \%$ had problems in obtaining an anaesthetist, $17 \%$ thought the first on-call anaesthetist was too inexperienced and $5 \%$ had experienced various other problems. Overall, $20 \%$ were unhappy with the service.

Key words: anaesthesia, general anaesthesia

\section{INTRODUCTION}

General anaesthetics are administered in many accident and emergency (A\&E) departments, either as part of the resuscitation of seriously ill or injured patients - for instance, those suffering from head injuries or drug overdosage - or for elective procedures such as the drainage of abscesses and the manipulation of fractures. A previous study' has shown that the provision of this anaesthetic service is fraught with many administrative problems.

Several changes in working practice have now been introduced which may have an effect on the provision of anaesthetic services to A\&E departments. The reduction in working hours of junior doctors, higher standards required for monitoring patients during anaesthesia and the provision of trained anaesthetic assistants have resulted in many departments finding it increasingly difficult to maintain the same level of service to their A\&E department. We therefore decided to investigate the current provision of anaesthetic services to A\&E departments via a postal survey.

\section{METHODS}

A questionnaire was sent to the consultant in charge of each of the 178 A\&E departments in England and Wales attended by over 30000 patients each year. The first part of the questionnaire asked for details of the annual numbers of emergency (defined as those given during the course of resuscitation) and elective (i.e. pre-arranged) general anaesthetics administered in the A\&E department and the grade and specialty of the person administering them. The second part was concerned with problems encountered with the administration of the anaesthetics. Finally, the respondents were asked whether they were satisfied with the anaesthetic service to their department and, if not, why not.

\section{RESULTS}

A total of 129 (72\%) replies were received, including several letters of comment.

The numbers of anaesthetics given are recorded in Table 1. In 61 (47\%) A\&E departments, no elective general anaesthetic was given and in six (5\%) no emergency general anaesthetic was administered. In those A\&E departments where general anaesthetics were given, the most frequent number of elective anaesthetics was 101-500 each year (26 hospitals) and for emergency anaesthetics 1-25 each year (49 hospitals). The median number was 1-25 each year for elective general anaesthetics and 26-50 each year for emergencies.

General anaesthetics, whether elective or emergency, are generally given by anaesthetists. However, A\&E staff administered occasionally in $21(16 \%)$ of the hospitals. These staff were either senior registrars or consultants, except in two cases where registrars were giving the anaesthetics. All the A\&E staff giving anaesthetics 
Number of hospitals giving this number of general anaesthetics

\begin{tabular}{ccc} 
Number of general & & \\
\cline { 2 - 3 } anaesthetics each year & Elective & Emergency \\
\hline 0 & 61 & 6 \\
$1-25$ & 10 & 49 \\
$26-50$ & 5 & 19 \\
$51-100$ & 7 & 13 \\
$101-500$ & 26 & 14 \\
$501-1000$ & 4 & 4 \\
$1001-5000$ & 0 & 1 \\
Don't know & 16 & 23 \\
\hline
\end{tabular}

Table 1. Numbers of general anaesthetics given annually had anaesthetic experience, although generally this involved not more than one year in an anaesthetic post.

The grades of anaesthetist most often involved in the A\&E department were senior house officers (SHOs) and registrars (Table 2). Senior house officers were always first on-call for A\&E in $17(13 \%)$ of the hospitals and registrars in $15(12 \%)$. The most common arrangement was for either the SHO or registrar to be called, depending on availability (47 hospitals). Anaesthetic consultants give anaesthetics in A\&E departments in $\mathbf{3 0}$ of the 129 hospitals $(23 \%)$, but in only 10 of these were they always involved and only two had scheduled elective lists in the A\&E department.

The most common problem associated with the administration of general anaesthesia in A\&E was a delay in the arrival of the anaesthetist (31 hospitals) (Table 3). Staff in 12 (9\%) A\&E departments reported having to wait for the anaesthetic assistant to arrive, and in 13 (10\%) units that the anaesthetist had to call for senior

Table 2. Grade of anaesthetist administering anaesthetics

\begin{tabular}{ll}
\hline Grade of anaesthetist & No. of hospitals \\
\hline SHO always & 17 \\
Reg. always & 15 \\
SHO or Reg. & 47 \\
Any junior doctor & 5 \\
SR or consultant & 3 \\
Consultant always & 7 (2 had scheduled lists) \\
Any grade including & 20 \\
$\quad$ Consultant & 9 \\
Not sure &
\end{tabular}

help, causing further delays. In only two units were there problems with equipment. Respondents in $17(13 \%)$ units felt that the anaesthetist first called was too inexperienced - in all instances this was when an SHO was first on-call for the A\&E department.

Not all respondents who experienced problems expressed dissatisfaction. Among the 26 who did, nine felt the anaesthetist called was inadequately experienced, 14 had problems obtaining an anaesthetist rapidly and five described a combination of the two problems.

\section{DISCUSSION}

Generally there was a high level of satisfaction expressed in the survey. However, there is a significant level of dissatisfaction among A\&E consultants which needs to be addressed.

The most common problem quoted was difficulty in obtaining a suitably experienced anaesthetist. Forty (31\%) respondents reported this. This was usually due to delays in the arrival of the anaesthetist, but also because the anaesthetist, after assessing the situation, often had to call for more senior help, causing further delays. Among the concerns expressed in the 'comments' section

Table 3. Most common problems with general anaesthesia in A\&E departments

\begin{tabular}{lc}
\hline Problem & Frequency \\
\hline $\begin{array}{l}\text { Delays in arrival of } \\
\text { anaesthetist }\end{array}$ & $31(24 \%)$ \\
$\begin{array}{l}\text { Have to wait for assistant } \\
\text { Anaesthetist has to call } \\
\quad \text { senior }\end{array}$ & $12(9 \%)$ \\
Problems with equipment & $13(10)$ \\
\hline
\end{tabular}


General anaesthesia of the questionnaire were several involving lack of input from consultant anaesthetists, with comments such as 'no consultant dedicated to A\&E work, teaching etc.'. Another respondent felt that the junior anaesthetists who did cover his department were often 'reluctant to administer general anaesthesia despite the availability of full monitoring'. One consultant was concerned that the problems with administering general anaesthesia in the A\&E department lead to an 'inability to carry out elective minor procedures in A\&E - this leads to more admissions'. There were several comments about a lack of anaesthetic assistants, some exacerbated by a split-site situation, and one respondent commented that 'anaesthetists (are) reluctant to accept A\&E nurses instead of an ODA'.

Less general anaesthetics are given in A\&E departments now than 5 years ago. Thirty respondents commented that one of the causes of this was the inability to meet the new safety requirements recommended by the College of Anaesthetists on monitoring and anaesthetic assistance. ${ }^{2-4}$

There does not seem to be any easy solution to the problems of obtaining an anaesthetist quickly when he or she is in theatre, except to ensure that A\&E staff know who to call first and to be more prepared to call in senior staff early on. As more A\&E staff obtain anaesthetic experience themselves, this may become less of an issue. The problems with inexperienced anaesthetists could be addressed by putting registrars first on-call for A\&E rather than SHOs, and attempting to involve more senior anaesthetic staff in A\&E work.

There were only a few concerns expressed over a lack of equipment, which is probably a reflection on the effectiveness of the various guidelines published in monitoring standards. ${ }^{3}$ However, the lack of a trained anaesthetic assistant was a recurring problem, which could relatively easily be solved by better planning and training of the A\&E nurses themselves.

Interestingly, eight of the 17 respondents who thought the anaesthetist was inexperienced and 26 of the 40 consultants who had problems obtaining an anaesthetist were not unhappy with the service overall. This may reflect a generally low level of expectation, coupled with a relatively low frequency of administration of general anaesthesia, so that the problems encountered are perceived as being unimportant compared with other problems in the department.

There was a perception by some A\&E staff of the anaesthetist being unhelpful and dependent on multiple pieces of monitoring equipment. There was also a feeling that A\&E cover is given low priority by anaesthetists, an impression perhaps reinforced by the fact that only $23 \%$ were able to report consultants anaesthetizing in the $A \& E$ department.

\section{CONCLUSIONS}

The number of elective general anaesthetics performed in A\&E departments is decreasing, emergency anaesthetics are generally performed by junior anaesthetists and the level of service provided by anaesthetic departments to the A\&E department is in many instances poor. From the evidence obtained from this survey we recommend that anaesthetics in A\&E should not be performed by inexperienced SHOs, but by staff of registrar grade or above. If anaesthetic consultants became more involved with administering general anaesthetics in A\&E departments, this could improve both patient management and junior doctors' teaching and supervision. They could also ensure that the A\&E departments were appropriately equipped. The provision of elective lists in A\&E departments could bring similar benefits and also allow time for training A\&E nursing staff in anaesthetic techniques.

\section{REFERENCES}

1. James M.R. \& Milson P.L. (1988) Problems encountered when administering general anaesthetics in accident and emergency departments. Archives of Emergency Medicine 5, 151-155.

2. Association of Anaesthetists of Great Britain and Ireland (1991) The Role of the Anaesthetist in the Emergency Service Association of Anaesthetists, London.

3. Association of Anaesthetists of Great Britain and Ireland (1988) Recommendations for Standards of Monitoring During Anaesthesia and Recovery Association of Anaesthetists, London.

4. Association of Anaesthetists of Great Britain and Ireland (1988) Assistance for the Anaesthetist Association of Anaesthetists, London. 